Article

\title{
A Challenge-Based Learning Experience in Industrial Engineering in the Framework of Education 4.0
}

\author{
Yadira Gutiérrez-Martínez *, Rogelio Bustamante-Bello (D), Sergio A. Navarro-Tuch *(D), Ariel A. López-Aguilar (D), \\ Arturo Molina (D) and Inés Álvarez-Icaza Longoria (D)
}

School of Engineering and Sciences, Tecnologico de Monterrey, Calle del Puente 222, Ejidos de Huipulco, Tlalpan, Mexico City 14380, Mexico; rbustama@tec.mx (R.B.-B.); ariel.lopag@tec.mx (A.A.L.-A.); armolina@tec.mx (A.M.); i.alvarezicaza@tec.mx (I.Á.-I.L.)

* Correspondence: yadira.gutierrez@tec.mx (Y.G.-M.); snavarro.tuch@tec.mx (S.A.N.-T.)

check for

updates

Citation: Gutiérrez-Martínez, Y.; Bustamante-Bello, R.; Navarro-Tuch, S.A.; López-Aguilar, A.A.; Molina, A.; Álvarez-Icaza Longoria, I. A Challenge-Based Learning Experience in Industrial Engineering in the Framework of Education 4.0. Sustainability 2021, 13, 9867. https:// doi.org/10.3390/su13179867

Academic Editor: Jin Su Jeong

Received: 25 June 2021

Accepted: 26 August 2021

Published: 2 September 2021

Publisher's Note: MDPI stays neutral with regard to jurisdictional claims in published maps and institutional affiliations.

Copyright: (c) 2021 by the authors. Licensee MDPI, Basel, Switzerland. This article is an open access article distributed under the terms and conditions of the Creative Commons Attribution (CC BY) license (https:// creativecommons.org/licenses/by/ $4.0 /)$.
Abstract: Current tendencies of product, project and services development focus on a higher consideration of the User Experience (UX). Therefore, traditional training and teaching methodologies need to adapt to prepare the students to develop strategies for problem solving for their professional education. Such needs have risen and interest in tendencies such as education and Industry 4.0 has grown. This paper presents and analyzes the process and results of a teaching implementation methodology based on Challenge-Based Learning (CBL). The paper describes the process followed, explaining the methodology precedents that led to the final implementation case. It also mentions previous experiments on product analysis and home automation developments that are linked to implementation of the technology. This case's implementation, analysis and experimentation integrated the use of Emotional Domotics (ED) Tools for the UX analysis, to grant feedback and compare the students' results with the bio-metrical and emotional computational analysis. The methodology, described through this document, allowed the students to better understand and experience some of the implications of an interconnected system with instant information feedback. This allowed them to better grasp part of the impact that the tendency towards the Internet of Things (IoT) is currently having, and the impact of the improvement proposals from the students.

Keywords: educational innovation; higher education; CBL; UX; Industry 4.0; ergonomy analysis; emotional domotics

\section{Introduction}

Technology-based knowledge transmission, and the development of minimal necessary tools, in an information and communication-based society, presents various challenges and evolution requirements, as it has been forecasted by researchers in previous years [1-3], in order to achieve an optimal professional development. Some authors have stressed the importance of tasks as an element that links student motivation, student cognition, instruction, and learning [4].

The progress and advancements on technology throughout the different industrial revolutions [5] have allowed for what we may call educational revolutions. This is a continuous cycle, where advances in technology lead to the generation of different learning enablers as can be seen in the the table presented by [6]. The generation of such enablers in consequence allows the students to further develop and advance the technology, leading to industrial advancements. Some examples of the implementation of such enablers were documented in $[7,8]$. Even though the main focus during the current industrial revolution, that led to the Industry 4.0, is the use of technological advancements and digitalization [9-11], some of the advancements and contributions can also be found in the implementation of industrial methodologies like the TRIZ (theory for the resolution of inventive related tasks) such as the ones described by Bertoncelli et al. [12]. 
The Challenge-Based Learning (CBL), allows the student to develop tools and strategies to confront problems similar to what they may find in the professional development. Thus, serving as a development laboratory without the necessary financial consequences of such experimentation on an industrial scenario. The development of such strategies and educational tools implementation is urgent, as one of the main challenges of the industry transition into the digitalization systems is the high financial costs and the lack of qualified employees [5]. The first one can be regulated and reduced if the investment can produce an accelerated implementation due to adaptable and prepared prospective personnel. In this regard, educational strategies play a main role where the educator needs to understand that they are, in most cases, preparing the learners to overcome challenges of positions and decision scenarios that may not yet exist [13]. Hence the CBL needs to allow the students to develop decision, adaptation and learning tools to be able to prepare for emerging technologies, without forgetting the basics and principles of the disciplines. In these hands-on pedagogical strategies, the student becomes a builder of their own knowledge, while enhancing the understanding and engagement of the learner [14-17].

\subsection{Challenge-Based Learning}

CBL is a collaborative and active approach that promotes the students' collaboration with their peers, teachers, and experts within their communities and around the world. From such experiences, the students acquire deep knowledge of the reviewed topics, allowing them to analyze, handle and solve challenges, take action, share their experience, and enter into a global discussion about important issues [18]. This approach engages the student through creativity and innovation stimulation [19]. In addition to the development of disciplinary outcomes, this approach stimulates the student's motivation towards learning, through its connection with the industrial environment [20]. In CBL, the educator is tasked with creating an active learning environment that involves the students in the planning of their own learning [21]. The general framework for the CBL as expressed by "The Challenge Institute" (https:/ / www.challengebasedlearning.org/framework/, accessed on 18 March 2020), is comprised of three phases: Engage, Investigate, and Act. During the Engagement phase, the scenario is presented. Such an introduction must be attractive for the students, and should have a relevant impact in both the students' lives and society [22]. From this presentation, the main questions are to be detailed, as they will be the backbone of the challenge. The following phase, the Investigation phase, requires the students to explore the correlated aspects of the challenge and search for external specialists and sources. In this phase the teacher guides the students, allowing them to develop strategies and build their learning; he should not provide the final answer. Finally, in the Acting phase, the students develop and build their proposed solutions to the problem based on their previous research.

The challenge structure aligns with the new paradigms of Education 4.0, while contributing to the implementation of the new TEC21 Model [6] which among its characteristics looks to develop various competences of the students; Figure 1 illustrates the process followed for this case scenario. The full scenario and development are further addressed in Sections 2.1 and 2.4. 


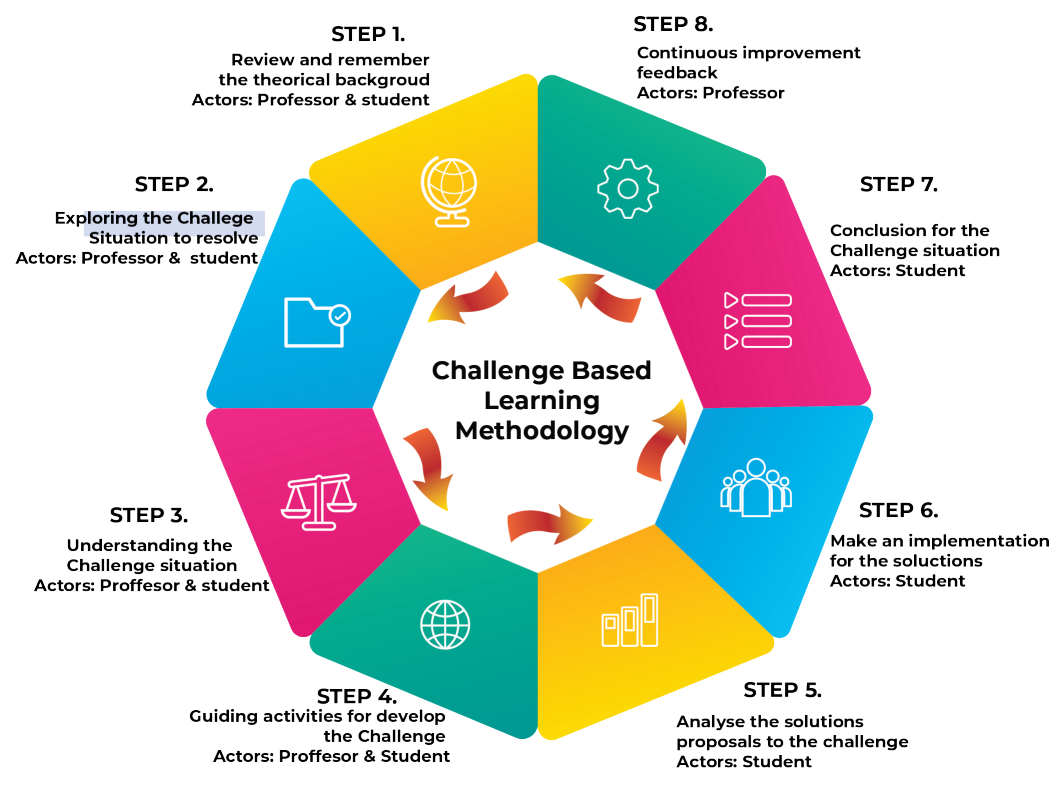

Figure 1. CBL Methodology process.

\subsection{Industry and Education 4.0}

The evolution of production processes in relation to technology is the main objective for Industry 4.0, moving from traditional techniques to the new era of digitalization [23]. This new industrial revolution focuses on a radical transformation of daily activities to achieve a highly productive performance. Although this does not imply that conservative processes and methodologies are unsuccessful, on the contrary, they generate reliable results attributed to the maturity of the process. However, technological progress makes these processes obsolete over time. This digital transformation of the industry will take place thanks to the concept of cyber-physical spaces, comprising as a "smart factory", storage systems, and production facilities capable of autonomously exchanging information, triggering actions and controlling each other independently. Moreover, the connection of the productive processes (physical) with the virtual world and the digital networks to achieve a higher level of control and process optimization becomes possible. This "smart factory" allows individual customer requirements to be met, whilst efficiency obtained in automated production is maintained. This means that even one-off items can be manufactured profitably. In Industry 4.0, dynamic business and engineering processes enable last-minute changes to production and also offer the ability to respond flexibly to disruptions and failures. End-to-end transparency is provided over the manufacturing process, also facilitating optimized design and decision-making [24].

With all these changes the new concept of Industry 4.0 is pushing the restrictions of the traditional ways to work, by challenging students to rethink the traditional value chain for processes and ways to work through digital lens to help increase productivity and reduce wastage. The globalized market in which humans and material assets must be preserved for the survival of organizations, management systems based on continuous improvement play an important role in ensuring compliance with applicable legal requirements, risk management and the opportunities, as well as the achievement of the best working conditions. The implementation of Industry 4.0 in small and medium-sized companies can make a difference in the competitiveness they will have in the future. If they decide not to change, they could lose business opportunities in a highly globalized and competitive environment. Nevertheless, it is important to mention that the scope of Industry 4.0 is difficult to quantify at the moment and will require employee training for the acquisition of skills related to information management, computer-assisted production, predictive maintenance, etc. It is because of this constant need to absorb, adapt and implement new technologies and make them compatible with previously structured principles and technologies that the challenge 
described in this case study arose as an opportunity for the students to develop and test their knowledge tools.

\subsubsection{Industry 4.0 Effects}

Due to the revolutionary proposal of Industry 4.0, countries have begun to design plans to standardize the processes that facilitate the transition and ensure that all members of a company participate. One of them is the implementation of standards such as ISO 450001: 2018 [25], which is focused on Occupational Health and Safety Systems. This a primordial rule, because it helps to create a safe and adequate environment for workers and members of the company. That action has an impact on the competitiveness and sustainability of the company; in addition, it seeks to reduce costs caused by poor health and accidents.

To this end, the Standard provides systematic guidance to help organizations and businesses of all sizes and types provide safe workplaces, whether they are a non-profit organization, a ministry, a micro enterprise, or a global conglomerate. In economic terms, the International Labour Organization [26] has estimated that more than $4 \%$ of the world's annual GDP (gross domestic product) is lost as a result of occupational accidents and diseases.

Among the benefits of implementing the ISO 450001 [25], which are referenced in Figure 2, we can mention the following important points:

- They provide elements so that an organization can reach and maintain higher levels of quality in the product or service.

- It provides an internationally recognized standard of prestige.

- It allows companies to reduce costs, achieve more profitability and increase productivity levels.

- It motivates and engages workers through consultation and participation.

- It facilitates relations with suppliers, customers and collaborators both national and international.

- It encourages implementation of continuous improvement processes

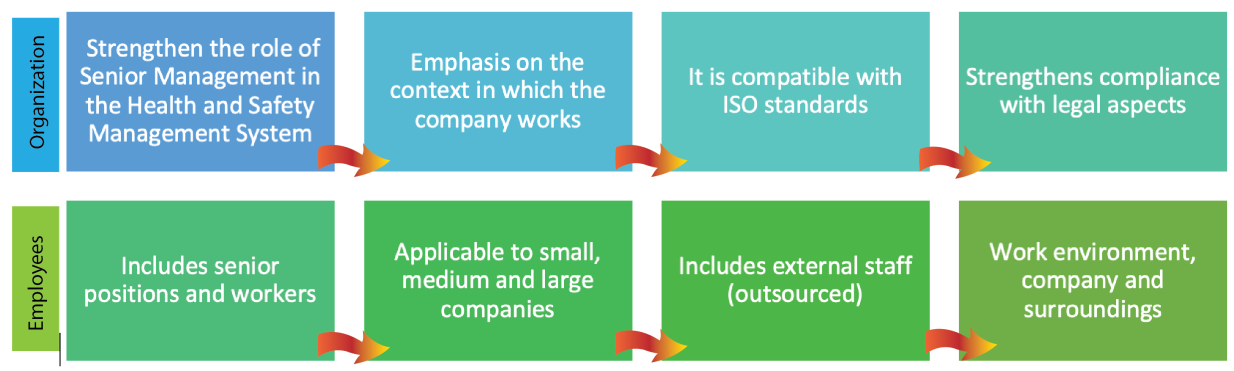

Figure 2. Main points on which ISO45001:2018 is focused.

\subsubsection{Education 4.0}

In a similar manner to industry experiencing a technological and methodological evolution, so has education been subjected to such an evolution. The relationship between the educator and the learner has experienced an evolution from the early stages of Education 1.0 to the recently defined Education 4.0 [27]. In the current phase, educators interact with a learner born in a digitally centered society, or what some authors have referred to as true digital natives. These digital natives are part of an hyper-cognitive generation, which has an impact on their demands towards the educator [28]. The demands made by the students force the educator to be open to a constant evolution and the corresponding improvement of their strategies and practices [29]. One of the recent approaches to the definition of Education 4.0 can be found in the model presented by Miranda et al. [27], proposing four core components, which will be briefly explained and related to the case presented in this article. 
The first component is the competencies, which result from the analysis and definition of the critical abilities and capabilities for the student to perform in their personal and professional environment. The competencies can be either transversal, which means they are independent of the knowledge area and centered on the personal and interpersonal development of the student, or disciplinary, associated to specific technical knowledge of an individual filed of study [27]. In the case of the study case in this article, the students' soft competencies developed were the Critical Thinking and Communication. The critical thinking involved immersion into the real case scenario, coupled with selection and implementation of the optimal tools to overcome the challenge. The communication competence was developed by the outcome generation and successful communication to the clients, who often included non-specialized listeners. The disciplinary competencies involved the use of industrial engineering analysis tools learned throughout higher education.

The second component is the learning methods; technology-based knowledge transmission and the development of the corresponding necessary tools, in an information- and communication-based society, force us to cope with various challenges and necessities, as has been forecasted by researchers in previous studies [1-3]. These necessities gain more and more importance, especially in the current world where complex engineering problems are no longer confined to an individual discipline of science or engineering [30]. Previous authors have stressed the importance of the provided tasks, as a central element for the linkage among student motivation, cognition, instruction and, in consequence, for the learning [4]. In the case presented in this article, the students are involved in a face-to-face learning strategy, where the learning experience is a result of the implementation of the CBL strategy presented in Section 1.1.

The third component of Education 4.0 needed for the successful implementation of the teaching strategy, is Information and Communication Technologies (ICTs). ICTs as a collection of technological resources that facilitate the access, distribution, and collection of information are an indispensable tool that contributes to the new ways of teaching, not just by their use, but in the way students and teachers can work in a collaborative manner to enhance the learning process by having knowledge accessible at any moment and sometimes without even being present in the same space [31]. The evolution of technology has made the integration of ICTs in higher education classes an important component with which to enhance a student's learning process. Some examples of ICTs are MOOCs [32], Virtual and Experiential environments [33], Educational Robotics [34,35], Web-based learning [36], Maker spaces [37], Mixed reality laboratories [38], M-learning [39], intelligent tutors [40], data science [41], machine learning [42], and cloud technologies [43]. For the case study presented in this article, the key technological player is Cyber-Physical Systems, which will be further discussed in Section 1.3.

The final component is infrastructure. Learning environments in Education 4.0 are supported by suitable facilities and tools to enhance learning and teaching practices which not only suit the learning needs of students but also support new pedagogical processes in the present educational context. Therefore, innovative virtual and physical facilities for learning, recreation, comfort, access and sustainability have been considered as part of the key components of Education 4.0. For this study case, we used the combination of the testing booth, seen in Figure 3, with the corresponding UX analysis tools FACET through iMotions ${ }^{\circledR}[44]$. In the following sections, the full scenario and conditions will be further developed. 

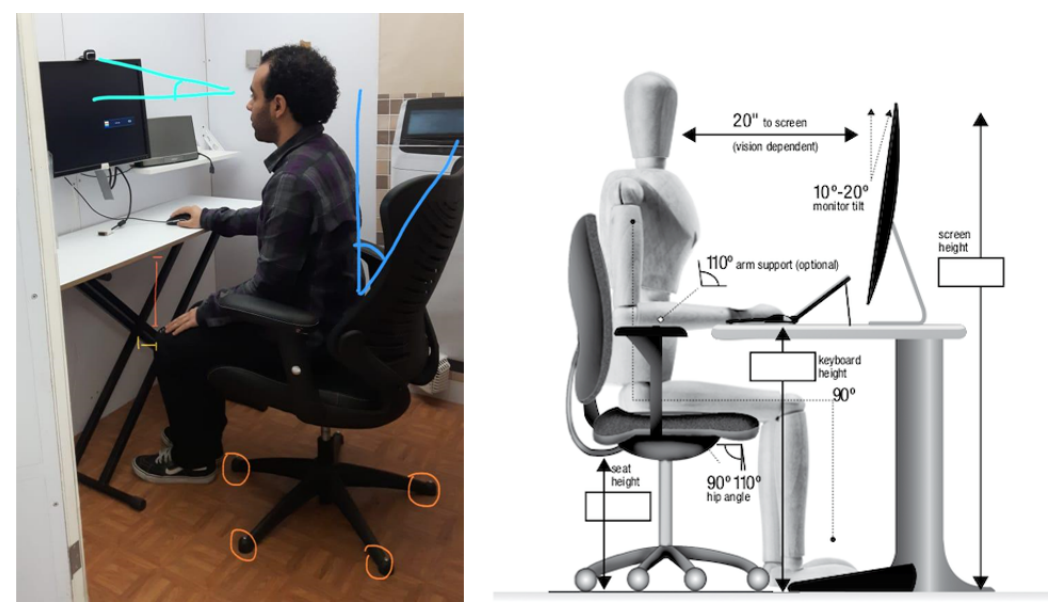

Figure 3. Analysis of the user's posture during the experiment.

\subsection{Cyber-Physical Spaces}

The generation of cyber-physical spaces that improve the ergonomic environment [45] will help in the representation of different scenarios, which may open the field of study to more and better adaptive features that can better integrate the client and have more complete studies and more information about the perception of the products and/or services. That is why the UX experiment, which the students analyzed for the study case, has among its long term objectives the creation of cyber-physical spaces adaptable to the needs of the client. In this case, the living room is fictitiously designed to simulate a real situation where the user evaluates the characteristics of certain products. Common research techniques such as surveys, interviews, questionnaires, focus groups and others may be affected by the performance of the researcher, impacting their effectiveness. For greater precision of results, it is desirable to evaluate from scientific, technological and standardized parameters. This kind of evaluation has the purpose of maximizing the probability of implementation, leading to work with standardized tools, which means programs already developed and highly validated in the scientific field for the facial recognition of emotions. These new techniques that intend to allow an accurate assessment of the neuronal activity are what led to the development of the research described in the following section.

\subsection{Ux and Emotional Domotics}

In previous works, the concept of emotional domotics (Home automation) has been developed $[46,47]$ and presented. From those studies some fundamental concepts are: Home automation (domotics), which refers to the integration of the different technologies in the inhabitable space through the simultaneous use of telecommunications, electronics, informatics and electricity. In addition, its purpose is to improve the quality of life of human beings [48]. Traditional Home automation technologies are designed to respond and react to environmental variables such as temperature, light intensity, humidity, etc. The approach that the research team $[46,47]$ has been using is the application of such technology for the generation of a system capable of responding to the user's state (either physiological or emotional). The project's structure allowed for the diversification and implementation of the developed tools for the UX analysis for products and of services. To understand the impact of the UX on the final system and product acceptance, we need to understand what the UX is. In the ISO UX is understood as the user's perceptions and responses that result from the use and/or anticipated use of a system, product or service [49]. Other authors consider that for the case of environments, the UX design requires the possibility of the user manipulating or controlling the system [50]. However, a characteristic of both approaches is that the UX can be established by basically the sum or flow of feelings that the customer experiences when using your device, web page, or system [51]. The experiment designed with the tools described in this section, to analyze the physiological and emotional response of the user while comparing it with their responses to surveys and interviews to contrast it 
with the UX, is the scenario of the Challenged used for the learning experience as detailed in coming sections.

\section{Materials and Methods}

\subsection{Scenario Description}

The program of B.S. in Industrial Engineering with a minor in Systems Engineering has the following educational objectives that the graduates must cover:

- Performs successful planning, design, installation, operation, evaluating and optimizing work systems that assure organizations' competitiveness through the use of industrial and systems engineering tools.

- Being up-to-date in their knowledge and grasp of concepts, methodologies and tools of industrial and systems engineering and other areas. They should also have the capacity to adapt rapidly to changes in their work environment, in a globally competitive setting.

- Interact with and influence the organization by leading work groups.

- Showing initiative and entrepreneurial abilities.

- Consider social and environmental sustainability issues when making decisions.

- Respect people and the environment, and make decisions based on ethical criteria.

According to the objectives of the program, the students of the program are subjected to develop Different Students Learning Outcomes, also referred to as competences, throughout the subjects in the study plan, declared under the standards of the international ABET certification that endorses the program. The full list of competences for the graduated students is listed next:

(a) An ability to apply knowledge of mathematics, science and engineering;

(b) An ability to design and conduct experiments, as well as to analyze and interpret data;

(c) An ability to design a system, component, or process to meet desired needs within realistic constraints such as economic, environmental, social, political, ethical, health and safety, manufacturability, and sustainability;

(d) An ability to function in multidisciplinary teams;

(e) An ability to identify, formulate, and solve engineering problems;

(f) An understanding of professional and ethical responsibility;

(g) An ability to communicate effectively (3g1 orally, 3g2 written);

(h) The broad education necessary to understand the impact of engineering solutions in a global, economic, environmental, and societal context;

(i) A recognition of the need for, and an ability to engage in, life-long learning;

(j) A knowledge of contemporary issues;

(k) An ability to use the techniques, skills, and modern engineering tools necessary for engineering practice.

\subsection{Course Context}

For this case, the UX experiment was developed in the course "Operational Design and Optimization Laboratory", for which the main purpose of this advanced industrial engineering course (8th semester of 9) is to integrate students' knowledge of classic industrial engineering, value creation and optimization models through a hands-on laboratory experience. The course requires previous knowledge of production management, added-value activity concepts, process maps, and process-optimization tools. The intended outcome of this course is for students to be able to apply the knowledge acquired during their course of study to the design, analysis and improvement of production processes by means of a laboratory experience. This course intends to develop and reinforce the following competences for the students:

- b. An ability to design and conduct experiments, as well as to analyze and interpret data; 
- e. An ability to identify, formulate, and solve engineering problems;

- $\quad$ k. An ability to use the techniques, skills, and modern engineering tools necessary for engineering practice.

Based on the student outcomes that the students are required to develop in the course, this experiment required the development of the following methodology in reference to specific learning objectives by topic:

1. Obtain information through mapping of the system to be studied, diagnosis of the current situation and definition of the problem using diagnostic tools and specialized software.

2. Generate the idea of the system that provides the expected service and establish alternative solutions using specialized software.

3. Evaluate the solution alternatives through economic, technical and human resources criteria using evaluation tools through specialized software.

4. Plan and schedule the solution implementation project as well as control the execution of the project through specialized software.

5. Present the results orally and in writing.

The major design experience that prepares students for engineering practice is this kind of subject with real experiments. In their last semester, students are prepared for engineering practice, developing a major design experience project based on earlier courses of the program and incorporating appropriate engineering standards (such as Project Management Institute (PMI) standards), the disciplinary body of knowledge, and multiple realistic constraints such as those emerging from contemporary issues of ethics, citizenship and sustainability concerns.

\subsection{Case Context}

For the case presented on this paper, the students of the I. E. bachelor program were taught about the basic elements of the project and witnessed the implementation methodology for a container redesign's UX analysis. The challenge-based experience of the students implicated a collaborative learning experience in which teachers and students collaborated to identify the possible issues, propose solutions to real problems, and take action. The approach asks students to reflect on their learning and the impact of their actions and publish their solutions to a community audience, these elements are similar to those defined in Bloom's challenge wall [52], in which the students first received a guide through previous courses on process analysis, work space norms, statistical considerations, and work space ergonomics. From that previous experience, the challenge required that the students completed the following tasks:

- Understand the basis of the implemented technologies.

- Evaluate the experimental protocol and implementation.

- Identify potential risks for the process, users or tools.

- Identify areas of opportunity for either the process or the designed instruments.

- Determine the required improvements for future iterations.

- Prepare a complete systematic report and manual to be used by future teams of researchers and designers.

- Present and defend their conclusions in front of the clients (in this case the researchers).

The challenge implementation's objectives were the integration of the knowledge of multiple courses in their career with the corresponding understanding and to demonstrate the impact of each element as a part of a whole to a client with a different specialization. For the challenge, the students needed to consider and implement the following knowledge areas of their major:

- Evaluation and optimization for continuous improvement;

- Process analysis;

- Ergonomy analysis. 


\subsection{Development of the Implementation}

The scenario of the challenge, establishes the process followed for a product UX analysis experiment conducted by the research laboratory for the evaluation of products implementing the tools described in Section 1.4 such as the testing booth. The components and tools evaluated during the challenge are described in this section, and illustrated in Figure 4 . The process brought about areas to improve the way in which the sequence of steps is carried out and, therefore, improve the UX.

\subsubsection{Theoretical Background}

As a first step, the students were introduced to the scenario and, through additional research, attain the theoretical background. Among the main topics reviewed were: Ergonomy, Design of experiments, Quality control, Productivity and Project Management.

\subsubsection{Workstation Design}

In this stage, an initial approach with the client was organized, leading to the following definition of objectives, variables, sample size and deadlines. The students arrived at the following definitions:

1. Definition of the challenge: The main objective for the client was to evaluate a new seasonal packaging proposal through the sensory experience of the user to identify according to certain variables, which were the designs that should be launched to the market according to the season of the year.

2. Objectives:

- Analyze the process that takes place in the domotic laboratory for the evaluation of a product through the sensory experience and facial expression of the user.

- Propose improvements in the generation of the process that are repeatable for future evaluations of products and/or services.

- Propose improvements in the external environment of the emotional domotic cabin to improve the user experience.

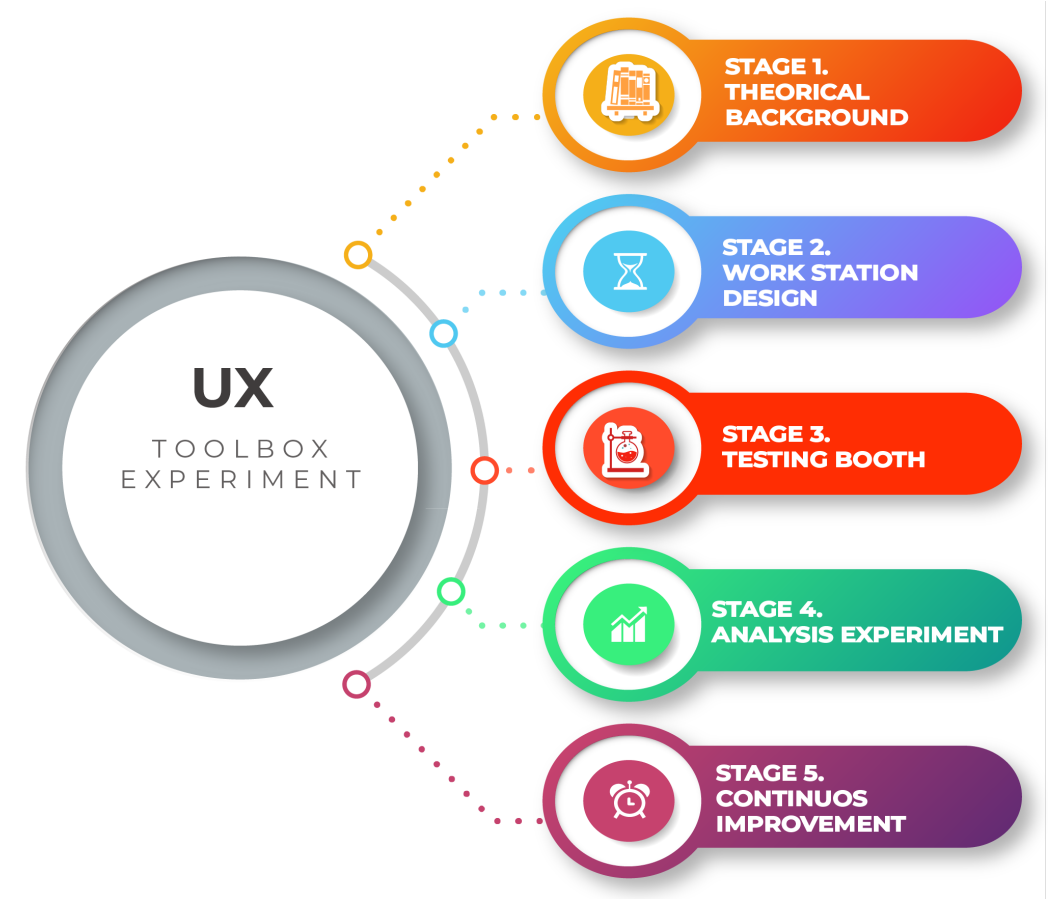

Figure 4. UX methodology analyzed during the CBL project. 


\subsubsection{Testing Booth}

During this stage the students are confronted with the challenge of understanding, analyzing and identifying key elements of a new technology, while integrating their previous knowledge to systematize and define the process threats and opportunity areas. This tools also granted the students a chance to explore and contrast the scenario with ideal standards and statute recommendations. The activities conducted by the researchers in this phase included the development of tests for data acquisition and the transcription of the data into the processing algorithm. The test conditions were designed to imitate the environment in which the consumer is expected to use the final product.

\subsubsection{Analysis Experiment}

As was mentioned above, the tools implemented into the scenario were new to the students, so in this phase, after developing a previous analysis, they were presented with the experimental results. in this way, they were able to contrast their initial findings with the user's reaction, and either identify additional opportunity areas, or reject previous hypotheses. The results and data presented to the students included the following elements monitored during the experiment recording:

- Facial expressions;

- Heart rate;

- Galvanic skin response;

- Mouse cursor recording;

- Scene recording;

- Temperature;

- Humidity;

- Light hue.

\subsubsection{Continuous Improvement}

In this final phase, the students compile and present their findings and conclusions to the clients (the research group), based on the completion of the tasks mentioned in Section 2.1. Some of the areas that the students made recommendations on were the testing space, covering the testing booth and the surrounding area and the implementation protocol, as it is fully presented and described in Section 3.1.

\section{Results}

While the first steps of the project required the students to document about the current methodologies and protocols implemented, together with the cause for each element. The next task was to observe the application of the designed protocol, which they documented and generated the expected time frames and process maps to describe and measure the outcome. The comparison of the results from the analysis tools such as the Galvanic Skin Response, the Photoplethysmogram (PPG) and the facial expression analysis was collected and later showed to them. Such data were analyzed and compared with the users reported experience and the students' personal experience as test subjects. This result led to the determination of the additional measurements necessary to evaluate, such as the adequacy of the position of the user for the interaction task with the product. The proposed areas of improvement detected and suggested by the students can be divided in three areas, the protocol, the testing space and the use of alternative tools.

\subsection{Students' Experience Results}

The students activity and solutions proposal for continuous improvement followed a structure depicted in the Figure 5. The Results for each element mentioned in the structure are detailed in the following points: 


\section{Results for the UX Experiment}

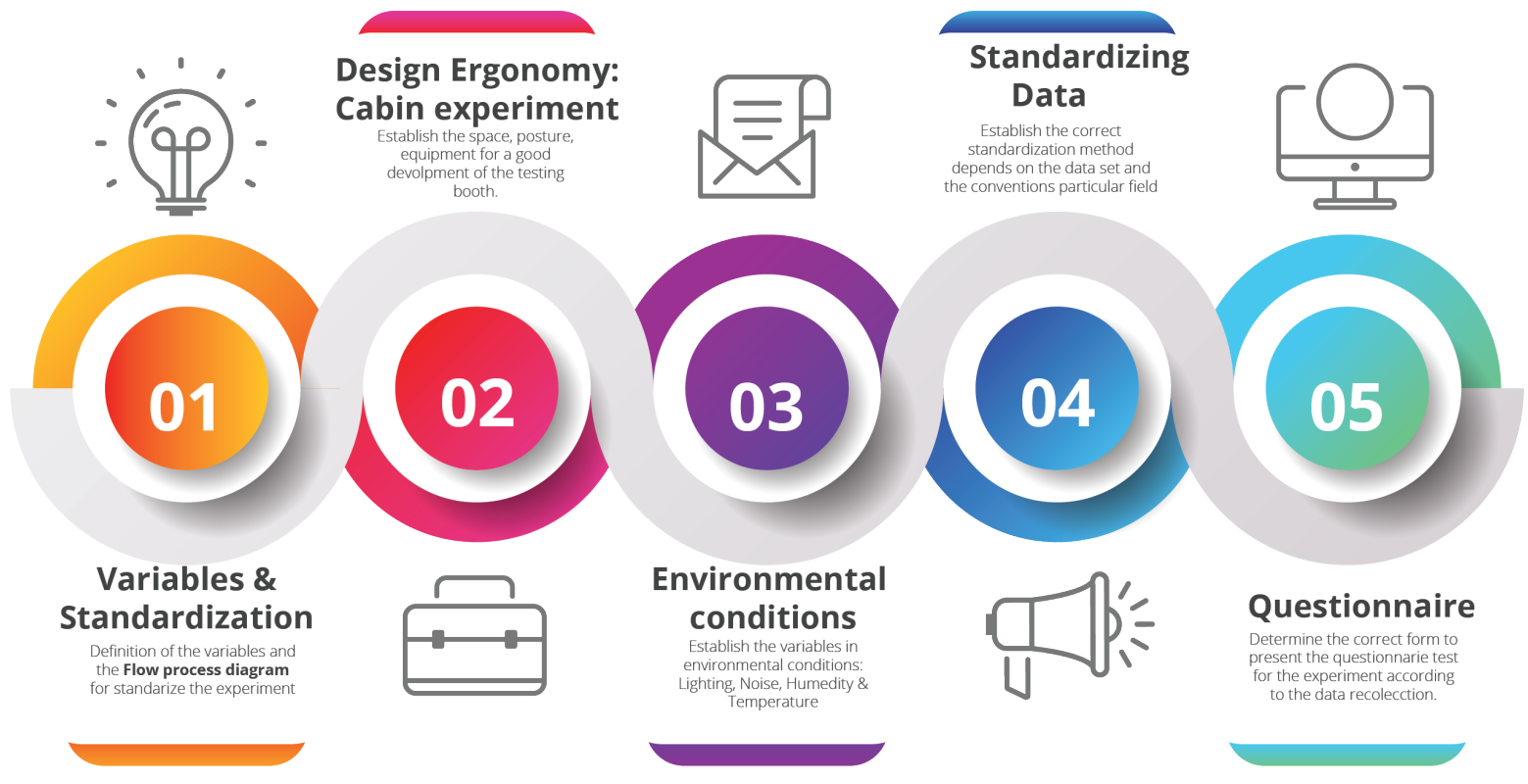

Figure 5. UX Results during the CBL project.

1. Variables and Standardization: prototypes, variables, materials For the development of this experiment, the data collected in Table 1 provided by the client were considered:

The relevant variables to be analyzed with each bottle were determined by the client and were the following:

- First impression;

- Bottle's grip;

- Dosage measurement;

- Spill prevention;

- Comparative quality against other bottles;

- Year season evocated by each bottle's design;

- Residue prevention.

For the UX analysis during the experiment, the users facial expressions, galvanic skin response and heart rate were measured. To better understand the product evaluation process by the experimental subject, one may use the diagram in Figure 6. The knowledge and the veracity of the times established in the previous diagram were provided directly by the home automation laboratory. In the table, it is marked in red the activity with the longest duration, and critical impact on the process optimization. The final result was a total time of $34 \mathrm{~min}$ and $50 \mathrm{~s}$ ( $35 \mathrm{~min}$ ), since the cabin is prepared until it is ready to receive the second person who will perform the experiment and, in order to understand the information contained in the diagram, it is important to mention the following particularities about it:

- Blue Activities: are those performed by laboratory technicians and must be performed in that time by internet connections and the time that the machinery and computer equipment needs to start.

- Green Activities: are those that take place when the sample of users that will carry out the experiment arrives.

It is important to reiterate that this process flow diagram begins at Stage 3 of the project: execution and control. The previous stages (initiation and planning) are not considered in this diagram. 
Flow diagram. Students' findings: The total time in the flow diagram, which both operators (the controller and the one in charge of interacting with the user) take is $35 \mathrm{~min}$. This time ranges from the preparation of the cabin until the second person is ready to enter to perform the experiment. Additionally, it was found that the longest time invested by the users (in conjunction with the operators) occurred during the placing of the shimmer sensor and in the reading and confirmation of their data, that is, a total of $6.2 \mathrm{~min}$ is allocated, per user, which makes the total process time increase too much for all the participants.

2. Design Ergonomy: Cabin Experiment As can be seen in Figure 3, regarding the user's position in the testing booth's seat, it can be seen that it is not in the recommended ergonomic position Figure 3 (image on the right). In the first instance, it can be noticed that the chair does not have wheels on the lower part, which makes its movement difficult. The second point that can be noticed is that the user does not rest his back on the seat, which may be a cause of future lumbar pain and discomfort in the lower back, upper back and neck. Another aspect that can be seen is that the table does not allow the user to be completely attached to the desktop by the base it has. The cross (support) of the table does not allow the user's knees to be under the table nor the extension of the arms to reach the mouse comfortably. Finally, it can be noted that the top edge of the monitor is above the user's vision. This, in the long term, causes tired vision and may have an influence on the results due to the fact that the camera is indispensable in this type of analysis.

After the analysis, the students' remarks and proposals to improve the testing space capabilities are the following:

- Modify the furniture to allow the user to sit comfortably, this may include returning the mobility to the chair to allow the approximation of the seat to move into the recommended position.

- Change to a chair that does not have fabric so that odors are not retained.

- Allow adjustment of the chair's height.

- Switch to a table where it is possible for the knees to enter underneath (avoid the cross support to avoid damage).

- Have a cushion for the back in case the user requires it and a bench for the feet if the case that this is also necessary.

- Regarding the height of the computer, it is recommended to have it on a movable base, so that it sits perfectly at the height of the operator's eyes, so that there are be no faults in terms of capturing their movements.

- Even though the population did not voluntarily express any dissatisfaction with the environment inside the cabin or with the furniture occupied, a questionnaire was not applied on the environment in which they interacted during the test to understand their opinion.

- Regarding the environment outside of the testing booth, the population expressed a discomfort regarding the place where the emotional domotic cabin was located. Given that the space was very small and cramped with boxes, people working and other laboratory materials, the first impression of the users was affected by the external environment in which they had to wait, beyond the test they performed.

3. Ergonomy: Environmental conditions The environmental conditions' ergonomy takes into account various aspects of the testing space. The aspects considered for this evaluation are the following:

- Ilumination In terms of lighting, the final tonality of the interior turned orange. Therefore, it is classified within Group One, defined for residential premises and for colder environments. This point is clarified later in lighting recommendations.

According to the NOM-025-STPS-2008 [53], the lighting intensity of the testing booth (82-93 luxes) is low if the visual activity is classified according to the 
standard. The visual tasks performed are simple visual inspection requirements, no assembly task or any other type requiring more detail of distinction is needed. However, if the Testing booth is considered as an interior, the minimum number of luxes would be equal to 100. Therefore, the lighting range of the place would be slightly below the norm.

- Temperature The interior temperature $\left(24-26^{\circ} \mathrm{C}\right)$ is within the permissible limits of the standard according to NOM-015-STPS-2001 [54]. The Ministry of Labor and Social Security indicates a maximum exposure of $4 \mathrm{~h}$ in a temperature range of 18 to $34{ }^{\circ} \mathrm{C}$. Therefore, there is no problem related to the norm, considering that the exposure time is only $9 \mathrm{~min}$.

- Humidity Similarly, the effective temperature of the work area shows a relative humidity of between $20 \%$ and $60 \%$, placing the humidity of the Testing booth $(>50 \%)$ within the limits. Despite this, in this section a series of recommendations are made to better shape the environment.

- $\quad$ Sound The National Institute for Occupational Safety and Health (NIOSH) and the NOM-011-STPS-2001 [55] recommends differing exposure times for different noise levels. The noise generated in the cabin is low noise (70\% volume), so it is not necessary to consider the exposure time. In addition, this time is relatively short and does not generate discomfort for the user. In any case it is important to consider the regulation at all times so as not to exceed the recommended duration. In Figure 7 we can see the noise exposure limits according to the NIOSH.

Based on this analysis and the conditions inside the testing booth during the experiment, the following recommendations were made by the students for the continous improvement:

- Illumination As previously mentioned, three different colors of lighting (green, red and white) are mixed inside the interior, which in the end create an orange shade perceived by the user. A recommendation is that the shades vary depending on the season in which the test is presented, warm colors in case the tests are in spring, intermediate colors in summer-autumn and cold colors for the winter season.

It is also important to express the desired message with the tonality of lighting. It is important to remember that the emotions and behavior of human beings depend on the environment in which they find themselves. The psychology of color associates different feelings based on color.

The orange hue is considered good for the interior of the passenger compartment. The orange color is a friendly and accessible color, associated with happiness and innovation. It also points out that it is a good option for residential spaces where you want guests to feel welcome. Therefore, it is an excellent option for the user to feel confident in the facilities.

As an alternative to this color, the use of the color blue is recommended since in the psychology of color, the meaning of the color blue is closely related to the sea and the sky. Stability, harmony, peace, calm and trust are just some of the feelings that can be generated in people.

In terms of lighting levels, the use of LED technology is recommended to reach the minimum levels of the standard. Some advantages of LED lighting are significant energy saving, long life, low heat emission, low light pollution, among others.

- Sound and Temperature The recommended sound, temperature and lighting vary depending on the day the test is performed. The recommendation is that it be carried out from Monday to Thursday for the different periods of the year. The ideal is to condition the cabin according to the place where you are going to buy the product. In this case, being a commercial product, the design of the cabin should simulate the appearance of a store with shelves and products of the same category. The objective of this is for the user to experience a real situation 
in a simulated environment and with real representative samples of each of the product families.

The test also allows a greater dynamism with respect to the assembly since, in a single day, the testing of only one season would be carried out, maintaining the same levels of sound, temperature, lighting and even the same aroma. This would avoid the changing of ambience according to the different seasons of the year, increasing the number of records made in each test.

The following scheme (Table 2) was designed taking into account the product that was being evaluated and the season that was intended to be emulated throughout the experiment (note: this is considering a Mexican household with an average temperature in the usage room):

The setting specifications are defined according to the first proposed questionnaire. This questionnaire is filled in by the company and based on whether the purchasing environment is planned, the season in which it is desired to apply it and the specific characteristics that are to be analyzed. It is important to adapt the booth to the relevant aromas and songs. An example of this would be to decorate the booth with lights and Christmas songs in the case of winter weather. Another recommendation within the same category of aromas is that the products to be tested have the scents of the original, if what you want is to know what product you want to buy in terms of the liquid and not in terms of the shape of the product.

4. Standardize Data: Analysis of Population for the Challenge The sample that the client provided for the sampling of the products cannot be considered a representative sample of the population due to the number of people who performed the experiment. This has as a consequence that the results presented by the cabin of emotional domotics have a low level of reliability and can be questioned. Given that 3 different product sizes were analyzed, the sample size of each of the families had to be calculated with the following formula [56]:

$$
n=\frac{k^{2} * p * q * N}{\left(e^{2} *(N-1)\right)+k^{2} * p * q}
$$

where:

- $\quad N$ : Size of the population or universe (total number of possible respondents). In this case, the client had to consider the number of people that are more likely to buy each of the sizes that were available due to their characteristics and needs. An example would be the number of women between 15 and 29 years old for family 1 of products $(600 \mathrm{~mL})$ that live in the CDMX.

Note: According to a study conducted by the National Institute of Statistics and Geography (INEGI) in 2015, 22.8\% of the female population in the CDMX complied with this characteristic, which represented 1,068,637 women in that year. This number would have to be further refined according to socio-economic level, brand preferences, etc.

- $\quad k$ : Constant that depends on the level of confidence that is assigned. The level of confidence indicates the probability that the results of the research are true: a $95.5 \%$ confidence is the same as a possibility of error of $4.5 \%$.

The most used $\mathrm{K}$ values and their confidence levels are listed in the Table 3:

- $\quad e$ : Desired sampling error. The sampling error is the difference that can exist between the result obtained by asking a sample of the population and the one that would be obtained if the total population was asked.

- $\quad p$ : Proportion of individuals who possess the characteristic of study in the population. These data are generally unknown and it is usually assumed that $p=q=0.5$, which is the safest option.

- $q$ : Proportion of individuals who do not possess that characteristic, that is $1-p$. 
- $n$ : Size of the sample (number of surveys that must be performed) for the tests; flow diagram of the process, and the adaptation conditions of the workplace, or area where it was carried out performing the sensory perception experiment; ergonomics.

5. Questionnaire Based on the users' perception analysis, it was determined by the students that the population did not show displeasure nor rejection at the time of carrying out the questionnaire, since it served as a complement to experience on the test that was applied to them; that is, the students considered that the questionnaire was answered with truth and conviction of what they had just received during the experiment.

\begin{tabular}{|c|c|c|c|c|c|c|c|c|}
\hline \multicolumn{9}{|c|}{ Flow Diagram Chart (Challenge Based Learning Emocional Domotics Test) } \\
\hline Diagram Num: $1 \quad$ Page num 1 of 1 & \multicolumn{8}{|c|}{ Resumen } \\
\hline \multirow{2}{*}{ Objet: 3 families of bottle } & \multirow{2}{*}{\multicolumn{4}{|c|}{$\frac{\text { Activity }}{\text { Operation }}$}} & \multirow{2}{*}{\multicolumn{2}{|c|}{$\frac{\text { Actual }}{1796.13}$}} & Proposal & Economics \\
\hline & & & & & & & & \\
\hline \multirow{2}{*}{$\begin{array}{l}\text { Activity: Perform the flow diagram of the product } \\
\text { evaluation process through sensory experience } \\
\text { Method: Analysis of physiological and sensory data }\end{array}$} & \multicolumn{4}{|c|}{ Transport } & \multicolumn{2}{|r|}{0} & & \\
\hline & \multicolumn{3}{|c|}{ Delay } & & \multicolumn{2}{|r|}{273.24} & & \\
\hline Place: Emotional home automation laboratory & \multicolumn{4}{|c|}{ Inspection } & \multicolumn{2}{|r|}{20.00} & & \\
\hline \multirow[t]{3}{*}{ Worker (s): 2 Analist (s): 1 Num Card: 1} & \multicolumn{3}{|c|}{ Storage } & & & 0 & & \\
\hline & \multicolumn{3}{|c|}{ Distance $(\mathrm{m})$} & & \multicolumn{2}{|r|}{0} & & \\
\hline & \multicolumn{3}{|c|}{ Time (man-min) } & & \multicolumn{2}{|c|}{34 min 50 seconds } & & \\
\hline \multirow{2}{*}{ Approved by: Ariel Lopez } & \multirow{2}{*}{\multicolumn{3}{|c|}{$\begin{array}{c}\text { Workforce } \\
\text { Total }\end{array}$}} & \multicolumn{3}{|c|}{\begin{tabular}{|l|l|}
3 & \\
\end{tabular}} & & \\
\hline & & & & Total & \multicolumn{2}{|c|}{34 min 50 seconds } & & \\
\hline Description & $\begin{array}{l}\text { Standard time } \\
\text { (seconds) }\end{array}$ & $\begin{array}{l}\text { Time per } \\
\text { section }\end{array}$ & & & bol & \multicolumn{3}{|c|}{ Observations } \\
\hline Adapt room & 99.31 & & $0 \mid \mathrm{c}$ & $\square$ & $\Rightarrow \nabla$ & \multicolumn{3}{|c|}{$\begin{array}{l}\text { Depending on the type of product or } \\
\text { service that is going to be evaluated. } \\
\text { Modify white lights and RGB lights. }\end{array}$} \\
\hline Prepare computer equipment & 705.10 & 824.42 & $\sqrt{5}$ & & $\Rightarrow \nabla$ & $\begin{array}{r}\text { Enter to Tean } \\
\text { over netwo }\end{array}$ & $\begin{array}{l}\text { n Viewer, en } \\
\text { rk, enter to }\end{array}$ & $\begin{array}{l}\text { nter to USB } \\
\text { imotion. }\end{array}$ \\
\hline $\begin{array}{l}\text { Verify that both the passenger compartment and the } \\
\text { computer equipment are in optimal conditions }\end{array}$ & 20.00 & & 0,5 & & $\Rightarrow \nabla$ & & & \\
\hline Receive participants & 120.00 & & 한 & 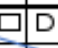 & $\Rightarrow \nabla$ & Problems with & h the reduce & ed space of \\
\hline Explain to participants the dynamic & 120.00 & & 05 & $\square D$ & $\Rightarrow \nabla$ & & & \\
\hline Place shimmer sensor and PPG sensor to the user & 378.00 & & ब1 & $D$ & $\Rightarrow \nabla$ & The user sign & is a consen & t letter and \\
\hline Wait until the user adapts to the room & 15.00 & 1071.85 & 05 & $\square D$ & $\Rightarrow \nabla$ & & & \\
\hline Carry out the test & 361.00 & & Q⿱宀 & $D$ & $\Rightarrow \nabla$ & From the start & of the test $u$ & until the user \\
\hline Remove shimmer sensor and PPG sensor from the & 38.93 & & 0 L & $\square$ & $\Rightarrow \nabla$ & & & \\
\hline Place shimmer sensor and PPG sensor to the next & 38.93 & & बर & D & $\Rightarrow \nabla$ & & & \\
\hline Rearrange room & 99.31 & 19309 & 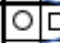 & $\overline{D D}$ & $\Rightarrow \nabla$ & & & \\
\hline Prepare computer equipment & 93.78 & 193.09 & O'L & 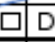 & $\Rightarrow \nabla$ & & & \\
\hline Total & 2089.36 & 2089.36 & \begin{tabular}{|l|l}
7 & \\
\end{tabular} & \begin{tabular}{l|l}
14 \\
\end{tabular} & $-1-1$ & & & \\
\hline
\end{tabular}

Figure 6. Flow diagram of the process (sequence of activities of the experiment).

Table 1. Data for experiment about product and population.

\begin{tabular}{cccc}
\hline Family & $\mathbf{1}$ & $\mathbf{2}$ & $\mathbf{3}$ \\
\hline BOTTLE'S SIZE & $600 \mathrm{~mL}$ & 1 gallon $(3.8 \mathrm{~L})$ & $5 \mathrm{~L}$ \\
Bottle's amount & 3 & 2 & 2 \\
\# Persons in test & 10 & 10 & 10 \\
\# of women & 10 & 10 & 7 \\
\# of men & 0 & 0 & 3 \\
Age range & $18-26$ years & $36-43$ years & $36-43$ years \\
\hline
\end{tabular}


Table 2. Table of environmental conditions associated to the four seasons in the laundry room for the environment emulation design.

\begin{tabular}{cccccc}
\hline Season & $\begin{array}{c}\text { Sound/Music } \\
{[\mathbf{d B}]}\end{array}$ & $\begin{array}{c}\text { Temperature } \\
{\left[{ }^{\circ} \mathbf{C}\right]}\end{array}$ & $\begin{array}{c}\text { Ilumination } \\
\text { [Tone Temperature] }\end{array}$ & [Lux] & Background \\
\hline Spring & $65-68$ & 26 & Warm & 95 & Laundry room \\
Summer & $65-68$ & 21 & Intermediate & 95 & Laundry room \\
Autumn & $65-68$ & 21 & Intermediate & 95 & Laundry room \\
Winter & $65-68$ & 18 & Cold & 95 & Laundry room \\
\hline
\end{tabular}

Table 3. Common $k$ values.

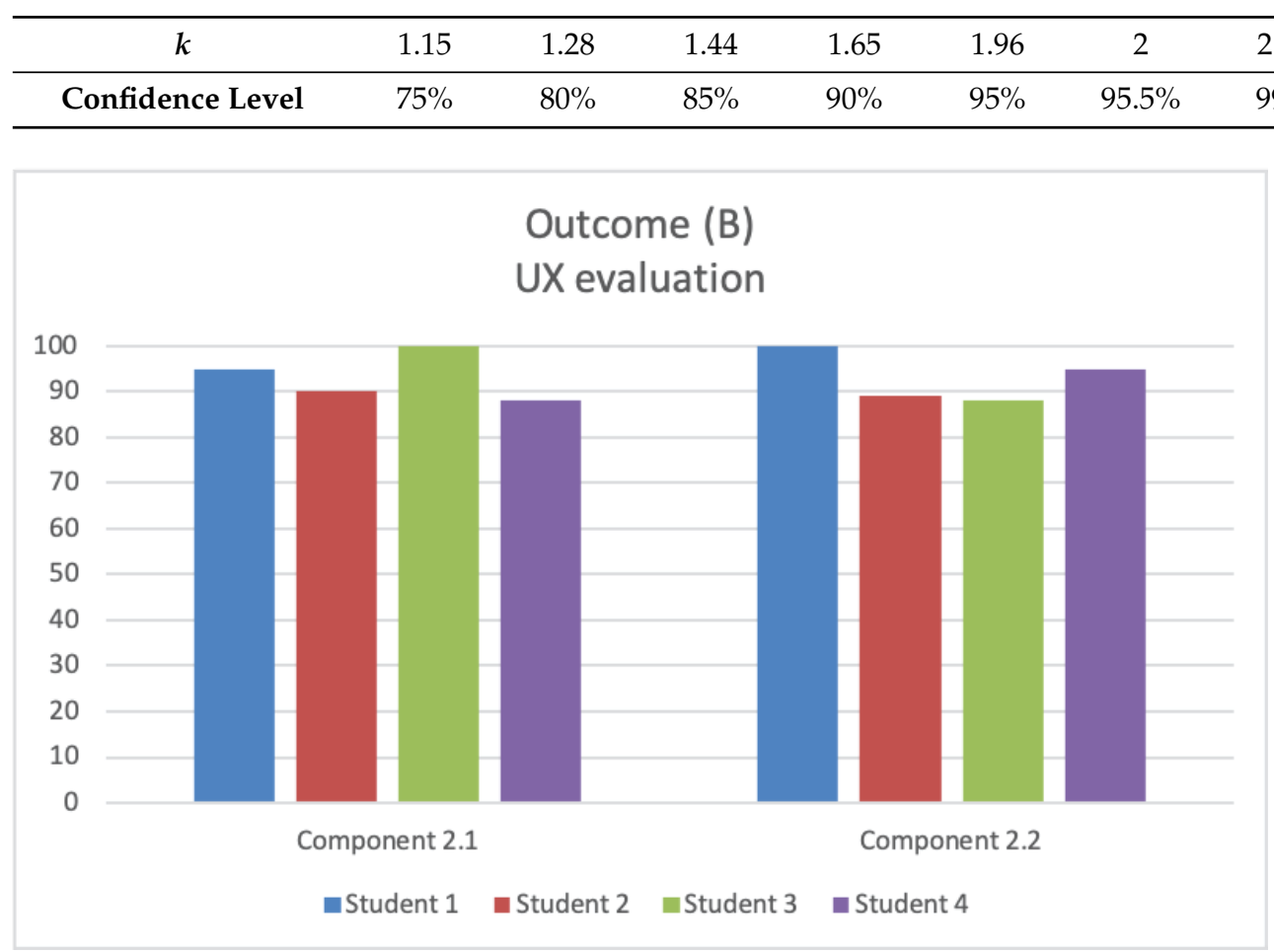

Figure 7. Noise exposure limits for a NIOSH operator [55].

\subsection{Methodology Implementation Results}

While the first steps of the project required the students to document the current methodologies and protocols implemented, together with the cause for each element, the next task was to observe the application of the designed protocol, in which they documented and generated the expected time frames and process maps to describe and measure the outcome. The comparison of the results from the analysis tools such as the Galvanic Skin Response, the Photoplethysmogram (PPG) and the facial expression analysis was later collected and demonstrated to them. Such data were analyzed and compared with the users' reported experience and the students' personal experience as test subjects. This result led to the determination of the additional measurements needed to evaluate, such as the adequacy of the position of the user for the interaction task with the product. The proposed areas of improvement detected and suggested by the students can be divided into three areas, the protocol, the testing space and the use of alternative tools.

This implementation being part of a interdisciplinary project that integrate areas such as biomedicine, UX, design and engineering, one of the aspects that were being studied by the design of the activity was the achievement level. The experience proved that, as previous authors have indicated, interdisciplinarity has become a critical issue in order to achieve an outstanding performance in our information- and knowledge-based society [57]. Hence, the creation and execution of projects that integrate in a satisfactory way multiple disciplines allows the students not only to fully grasp the theoretical background 
needed but they also develop tools and strategies to confront a real case scenario. Through the deep analysis and findings of the students (which were resumed in this document), the authors were capable of fully grasping the potential of the scenario and found that the potential of the applied CBL greatly exceeded the initial expectations. Then with some minor adjustments (among which is the challenge of guaranteeing an effective communication and integration among the involved majors), the methodology can be applied in future generations.

\subsection{Students' Academic Results and Perception}

The case presented and assessed in this article could be compared with other types of theoretical experiments that students realized during the two first years of their study plan in different courses. In these experiments there is a combination of theoretical knowledge, industrial laboratory tools, and the students' competences in the work design station simulator. In this experiment carried out in the testing booths [46], the student achieved the theoretical knowledge in contrast to the UX experiment that combined the real situation based on demand for a client's enterprise that needed a real test involving the design of new prototypes according to the users' needs and expectations.

In this case, the students were evaluated according to the corresponding competence rubrics and we obtained the following results for each outcome. It is important to consider that the minimum passing grade for each rubric is $70 \%$, otherwise the competence attainment level would be considered unsatisfactory. The results are present in the following graphics (a sample quantity), and refer to the competences mentioned in previous sections.

b. An ability to design and conduct experiments, as well as to analyze and interpret data. For this competence, the following components shown in the Figure 8 were evaluated:

- Component 2.1 Students demonstrate they are able to collect and process data;

- Component 2.2 Students demonstrate they are able to perform statistical analysis, interpret the results and write reports.

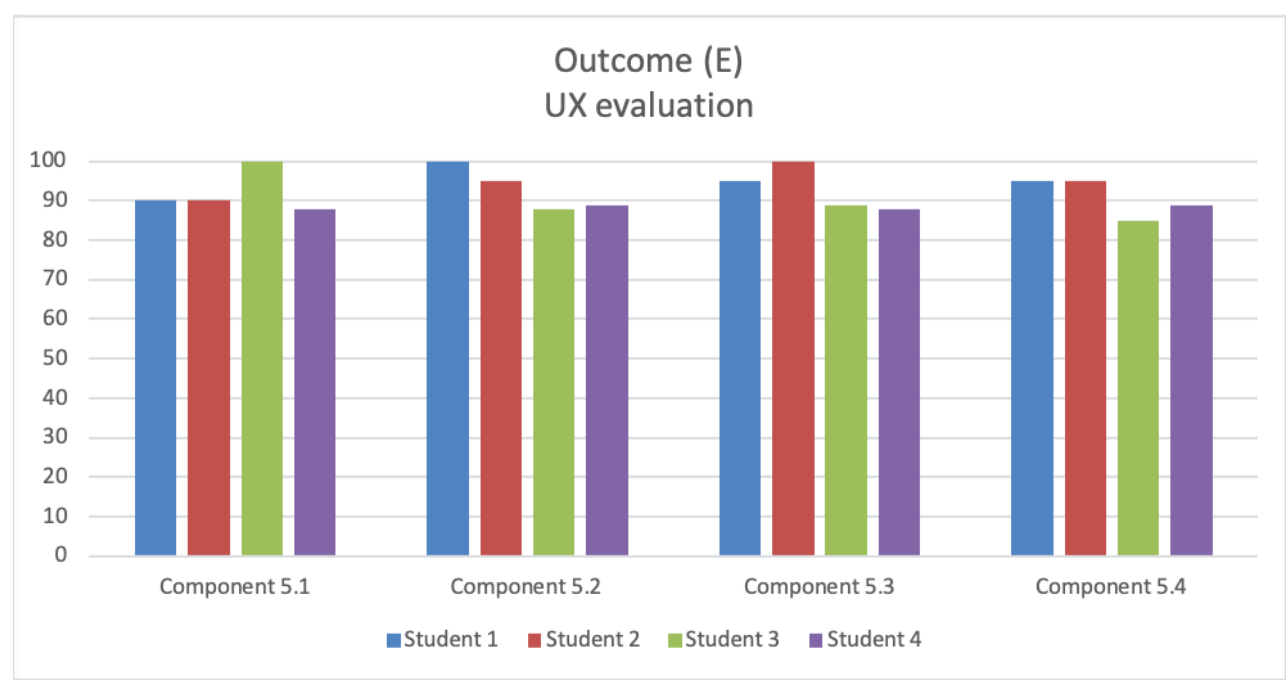

Figure 8. Competence b elements results sample.

e. An ability to identify, formulate, and solve engineering problems For this competence, the following components shown in the Figure 9 were evaluated:

- Component 5.1 Students separate the critical variables of a problem and reformulate the problems in order to understand their behavior;

- Component 5.2 Students make diagnoses to identify and describe a problem;

- Component 5.3 Students design and develop a solutions' action plan;

- Component 5.4 Students resolve a problem by implementing the solutions proposed. 


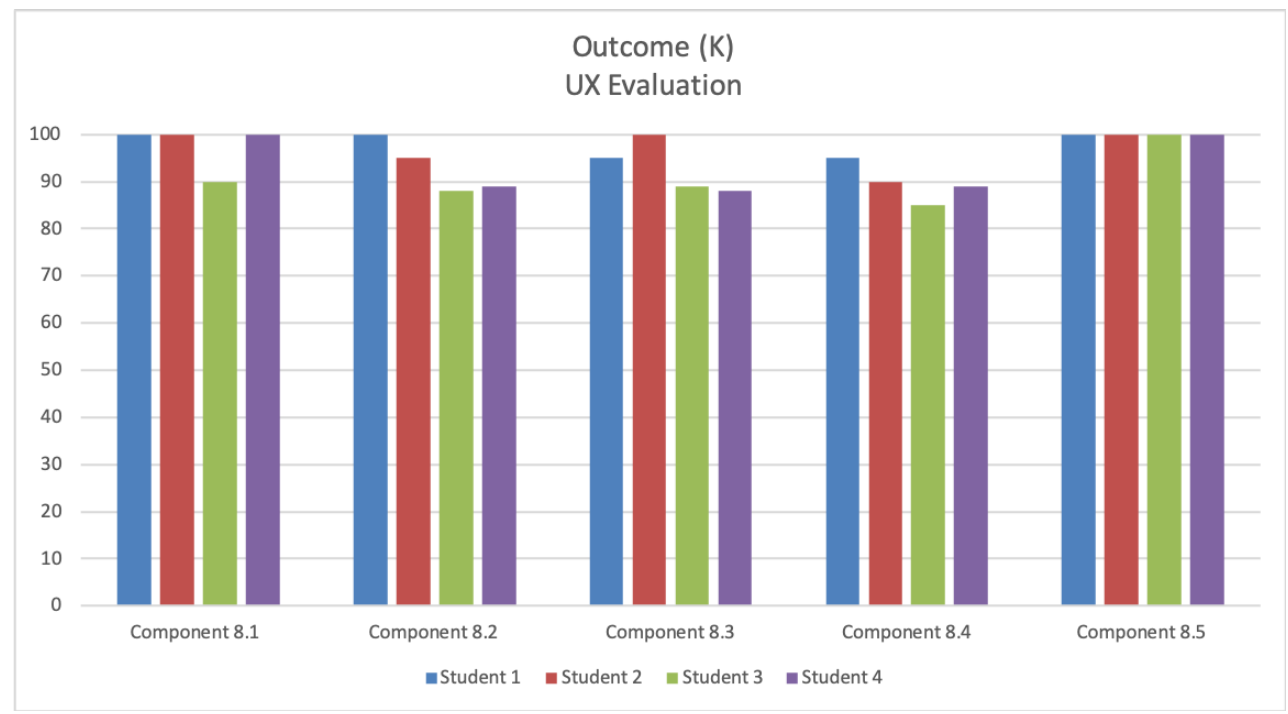

Figure 9. Competence e elements results sample.

k. An ability to use the techniques, skills, and modern engineering tools necessary for engineering practice. For this competence, the following components shown in the Figure 10 were evaluated:

- Component 10.1 Students satisfactorily prepare their integrative project in any type of organization;

- Component 8.1 Students show interest in learning in areas different from those of their profession if they register for topic courses different from the industrial and system engineering area;

- Component 8.2 Students develop projects in the industrial engineering area, using information tools adequately (internet resources, professional and technical magazines, manuals, etc.);

- Component 8.3 Students show interest in keeping updated in their profession as they have taken or are taking training courses outside the institution;

- Component 8.4 Students show interest in continuing their professional education.

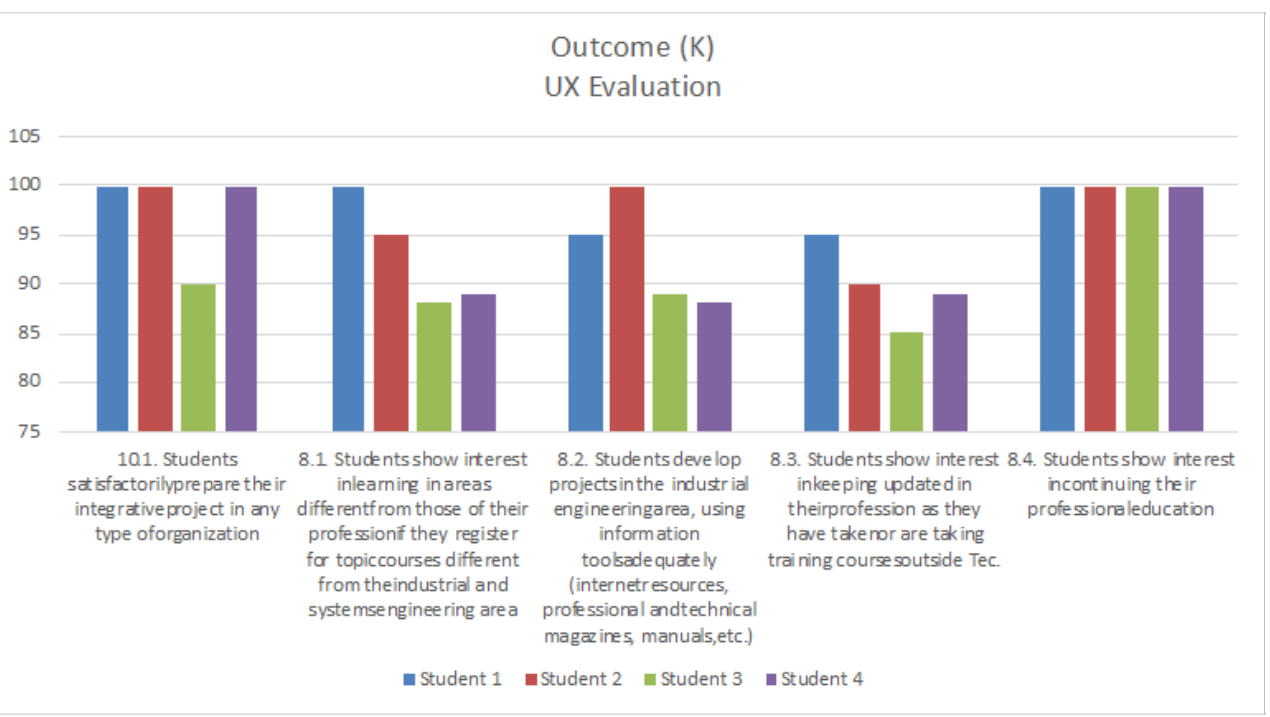

Figure 10. Competence k elements results sample.

The course had an important impact on the perspective of working on a real project in which the client's need was analyzed in order to determine the prototypes necessary for the launch of a new product. In this exercise for industrial engineering students, there was 
a clear example of the use of concurrent engineering, in which a group of specialists meet to contribute with their skills and knowledge, and thus make value-added products and services based on the requirements of the end market. The opinion of the students on this type of project was very positive; at the end of their academic semester students carry out an evaluation based on the learning process acquired throughout 18 weeks of class. In the final evaluation of the course, the students made comments for feedback such as:

- "The class is very interesting because it gives an avant-garde approach with current tools that will be handled in the professional field."

- "The project was very interesting, I had never done a project where we could unite disciplinary knowledge in two areas of development such as industrial design and industrial engineering."

- "The use of technological tools has been impressive; prior to this project I did not know that there is an evaluation of emotions and that they can be quantified and that these types of studies are the new trends that we will face in the world for various areas, it is very interesting how to be able to see the user experience and that from business decisions can be made."

\section{Discussion}

The implementation of this challenge-based learning experience allowed the students to integrate the knowledge and tools collected throughout their major and to confront a real case scenario where they acted as consultants. For the correct implementation of the challenge, the students first needed to learn about the analysis and methodologies implemented by the research group, for the UX analysis, in order to identify the reach, opportunity areas and limitations of such implementation. The students had the opportunity to act as experts on their area of study, while being confronted with the challenge of explaining, illustrating and demonstrating the importance of their findings to the clients whose expertise did not necessarily include the full background of the students. This process leads the students to develop competences related to the reasoning for confronting the complexity of the multifaceted challenge, communication in order to transmit their discoveries, and to collaborate with the multiple components of the team, and digital transformation through the understanding and implementation of state-of-the-art automatization and analysis tools.

Considering the results that were displayed by the students, and the initial objectives, in the context of Education 4.0, introduced in Section 1.2.2, we can observe that the methodology implementation was a success, thus reflecting the optimized interaction and relationship of the key components. This case successfully related the industrial engineering analysis from the students' disciplinary competencies acquisition with the communication skills of the transversal competence. The space analysis allowed the space to work as a source of information from an innovative ICT tool, while also being the experimental space to be analyzed through an ergonomic analysis.

The purpose of studying ergonomics and productivity in the experiment is to improve life quality through comfort. The user's comfort is of great importance when carrying out any types of activities. Poor posture or poor adaptation of work stations can cause irreparable damage in terms of health. This is why one should always try to achieve the welfare of operators through defined risk control plans. In this case, a series of recommendations are made based on the current conditions of the furniture and the cabin in general. The objective of this is simple, to improve the user experience with the help of ad hoc facilities to the experiment, guaranteeing stable and real results.

The generation of cyber-physical spaces that improve the ergonomic environment will help in the representation of different scenarios, which may open the field of study to more and better adaptive features that can better integrate the client and have more complete studies and more information about the perception of the products and/or services. That is why the experiment has as a partial objective the creation of cyber-physical spaces adaptable to the needs of the client. In this case, the living room is fictitiously designed to simulate a real situation where the user evaluates the characteristics of certain products.

Products and services' development through the user experience can guarantee the success of it. The Tryout phase of a product or service involves assessment by potential 
customers. This phase serves as a key point to determine its strengths and weaknesses in order to be able to work on those defects that it presents. It can be understood as a simple filter that guides the bidder regarding the first impact on the market. In this case, what is intended is to know the opinion of the user, through a questionnaire and a sensory analysis, about products from three different families. What is sought is to choose the optimal design of each of the products.

\subsection{Impact on Future Education}

Over time, education has been involved in a cycle of continuous evolution and improvement, responding to the innovations and industrial reforms introduced in the dayto-day life of a competitive world and perceived as a global system of interdependent relationships between individuals and organizations. Due to the great changes of the era that are taking place in the 21st century, according to Industry 4.0, the digital transformation of education is an unstoppable, irreversible, high impact process. Due to the need of the labor market for specific professional profiles of schools to face the new challenges of the productive sector in the 21st century, educational models must seek the formation of human capital suitable for industrial development, which is a common denominator in modernized educational institutions and meet the expectations arising from a social structure aiming at total automation. This Challenge-Based Learning is linked to a representative element of Education 4.0, related to the most important perspectives for the developing of learning as:

- Adaptive. This consists of designing learning ecosystems, face-to-face or virtual, according to the characteristics and needs of educators and students.

- Self-regulating. This assumes that the student is able to control their behavior and, consequently, be proactive in complex situations.

- Experimental. This creates educational situations where the student explores his or her skills to manipulate reality.

- Active. This makes the student an agent of change, rather than a container of information.

- Interactive. This fosters the relationship between the student and other agents, as well as with their environment.

- Collaborative. This implies that students achieve common goals by pooling efforts and resources.

- $\quad$ Problem-based. Involve students in solving real problems.

- $\quad$ Project-based. Involves students in carrying out an action plan focused on addressing a particular need or solving a specific problem.

According to the EDUCAUSE Horizon Report [58], the CBL project is a representative example of elements where innovative didactic strategies and cutting-edge learning perspectives converge, to develop talent capable of making creative and viable decisions, through a competency-based constructive approach, with the intention of achieving success in a digital-centered social or work structure.

In this sense, it is a key point in Education 4.0 to apply the challenge-based learning methodology for the development of Talent 4.0 through the approach, deployment and evaluation of specific programs focused on three key areas for Talent 4.0:

- $\quad$ Promotion of entrepreneurial talent.

- $\quad$ Promotion of STEM vocations and training in digital skills aligned with Industry 4.0.

- Promotion of dual training in cooperation with firms, particularly with the Engineering Development and Innovation Centers and the technology sector.

The impact of this CBL with this project established a new form for develop the professional outcomes for industrial engineering students, the students can achieve new abilities and skills with real projects as mentioned before, with the joint venture form as university-business alliance is a key element in the development of this learning for 
the training of future engineers in Industry 4.0 with the aim of aligning the university curriculum with the new competencies required by this globalized world.

\subsection{Cbl Vs Traditional Course}

As an innovative pedagogical tool, the CBL, requires a great deal of effort on the part of students, but also of teachers. In this case, the students were engaged in a real situation, relevant and related to their environment. It involves students working with stakeholders to define a challenge and collaboratively develop a solution that is environmentally, socially, and economically sustainable.

For these new tools it is important to highlight the aspects presented in Table 4:

Table 4. Comparative table of CBL course against Traditional Knowledge Course with PBL implementation.

\begin{tabular}{|c|c|c|}
\hline Characteristic & $\begin{array}{l}\text { Traditional Knowledge Course } \\
\text { Applying (Project-Based Learning) }\end{array}$ & $\begin{array}{c}\text { Challenge-Based Learning } \\
\text { Course }\end{array}$ \\
\hline Learning & $\begin{array}{l}\text { Students build their knowledge through } \\
\text { specifics tasks in the industrial laboratory, } \\
\text { according to the theorical needs, the } \\
\text { knowledge acquired is applied to carry } \\
\text { out the assigned project. }\end{array}$ & $\begin{array}{l}\text { Students work with teachers, experts, a } \\
\text { client (enterprise), on real-world problems, } \\
\text { in order to develop and applying deeper } \\
\text { knowledge of the subjects that they are } \\
\text { studying. } \\
\text { It is the challenge itself that triggers the } \\
\text { generation of new knowledge and the } \\
\text { necessary tools or resources. }\end{array}$ \\
\hline Focus of the course & $\begin{array}{l}\text { It faces the students with relevant } \\
\text { situations and predefined problems } \\
\text { for which a solution is required, } \\
\text { according to the theoretical purpose of } \\
\text { the course. }\end{array}$ & $\begin{array}{l}\text { It faces students with an open, relevant, } \\
\text { problematic situation which requires a real } \\
\text { solution. The develop also a multidisciplinary } \\
\text { work theme so the student had to develop } \\
\text { new abilities. }\end{array}$ \\
\hline Result of knowledge & $\begin{array}{l}\text { It requires the students to generate a } \\
\text { product, a presentation or an } \\
\text { implementation of solution of the different } \\
\text { practices }\end{array}$ & $\begin{array}{l}\text { It requires students to create a solution } \\
\text { resulting in a concrete action. }\end{array}$ \\
\hline Process knowledge & $\begin{array}{l}\text { Students work with the assigned practices } \\
\text { so their engagement generates products for } \\
\text { their learning, in the theoretical aspect as an } \\
\text { integrated project. }\end{array}$ & $\begin{array}{l}\text { Students analyze, design, develop and } \\
\text { execute the best solution in order to tackle } \\
\text { the challenge in a way they and other people } \\
\text { see and measure. For this project the students } \\
\text { developed a different scenario of solutions and } \\
\text { have tangible results. }\end{array}$ \\
\hline
\end{tabular}

In this new era of knowledge of Education 4.0, the CBL is one of the most important learning strategies that can achieve tangible results. It is necessary to have world-class training partners improving the level of uncertainty, the quality of the challenges, and the development of student competencies. All of this allows them to better prepare themselves for the work environment they will face at the end of their studies.

\subsection{Future Work}

Although this challenge delivered a high-level analysis and insight into the research methodology and systems, it also left the team with multiple tasks to cover in future developments. To this end, the testing space is in a re-design process led by industrial design students. Among the future tasks, we have to adjust and improve the evaluation technique, to integrate the original competences evaluation with the focused competences of the new education model of the institution. Another task is the building a larger portfolio of clients, to allow a greater number of students to participate in the dynamic reported here. This also implies that the team would need to either acquire more software licensed 
and build more testing spaces, or develop better time usage strategies. As previously mentioned, the testing space redesign is imperative, which involves also the relocation of such space, to diminish the impact that the environment surrounding it had on the test subjects before the experiment, and minimize the affectation that its usage had on the rest of the laboratories activities. In future assessments, it would be ideal to further involve the sponsor in the feedback of the students, and possibly in the final evaluation, which would also require the team to make sure that they either comprehend the competences, or design the evaluation forms in a way that they may be able to evaluate the competences without such training.

The implementation and documentation of this kind of experience facilitates the reproduction and further criticism of these strategies in different environments, thus allowing further improvement and development of strategies that nurture the education of the future industrial engineers. It may even be possible to extend such lessons and strategies to develop workshops that may even benefit working engineers thus favoring their adoption of techniques and tools beyond their usual toolbox.

\section{Conclusions}

As the Industry 4.0 is characterized by the three essential points mentioned before, more flexibility in the production process tailored to each individual customer, more speed to reduce the time needed to place the product on the market, and greater efficiency thanks to the analysis of data that allows digitalization and the IoT, in parallel new tendencies will be found in terms of education; the term Education 4.0 has three fundamental characteristics: flexible learning [59] according to the needs and interests of each student, learning at your own pace and at the speed of each student regardless of age and grade.

The implementation reported in this document allowed the students to experience the impact and difficulties of implementing their knowledge base built throughout their major, and visualize some of the challenges they will experience when integrating into a industry. However, the experience had some challenges and limitations to overcome. Among such limitations, we can find the low availability of resources given the time constraint and availability of the analysis software and the ideal test subjects provided. This constraints, for one limited the size of the possible students that could participate in the exercise without suffering a detriment in the experience quality, which lowered the size of our test sample. The other effect that these limitations had was that it lowered the chances for the students to test various hypotheses for improvement, although this forced them to be very cautious and analytic in their selection, which may be considered a positive experience. As for the possibility to implement the experience with more students, even though the bases have been settled, any future repetition would be without the sponsorship of this client, unless it is a new experiment; thus, exact repetition wont be possible, but a similar one is possible.

Author Contributions: Conceptualization, Y.G.-M., S.A.N.-T. and I.Á.-I.L.; methodology, Y.G.-M. and S.A.N.-T.; software, A.A.L.-A.; validation, R.B.-B.; formal analysis, Y.G.-M. and A.A.L.-A.; investigation, Y.G.-M., S.A.N.-T. and A.A.L.-A.; resources, A.M.; data curation, S.A.N.-T., A.A.L.-A.; writing—original draft preparation Y.G.-M.; writing—review and editing S.A.N.-T., I.Á.-I.L.; visualization, Y.G.-M.; supervision, Y.G.-M. and S.A.N.-T.; project administration, R.B.-B.; funding acquisition, A.M. and R.B.-B. All authors have read and agreed to the published version of the manuscript.

Funding: This research received no external funding, funding was provided by the CIMB as part of the Tecnologico de Monterrey.

Institutional Review Board Statement: Not applicable.

Informed Consent Statement: Informed consent was obtained from all subjects involved in the study.

Acknowledgments: The authors would like to acknowledge the financial support of Writing Lab, TecLabs, Tecnologico de Monterrey, Mexico, in the production of this work.

Conflicts of Interest: The authors declare no conflict of interest. 


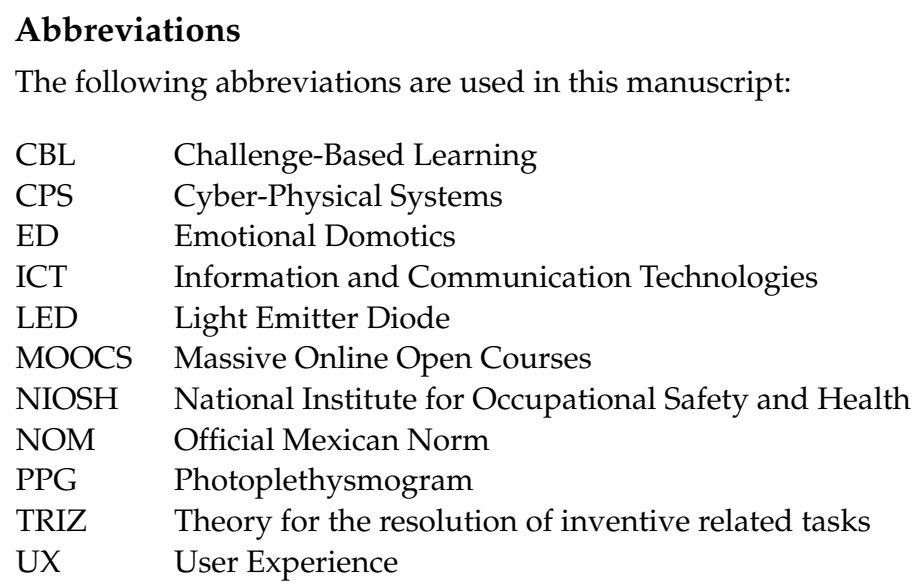

\section{References}

1. Marx, R.W.; Blumenfeld, P.C.; Krajcik, J.S.; Soloway, E. Enacting Project-Based Science. Elem. Sch. J. 1997, 97, 341-358. [CrossRef]

2. Frank, M.; Lavy, I.; Elata, D. Implementing the Project-Based Learning Approach in an Academic Engineering Course. Int. J. Technol. Des. Educ. 2003, 13, 273-288. [CrossRef]

3. Moti, F.; Barzilai, A. Project-Based Technology: Instructional Strategy for Developing Technological Literacy Moti. J. Technol. Educ. 2006, 18, 38-52.

4. Blumenfeld, P.C.; Soloway, E.; Marx, R.W.; Krajcik, J.S.; Guzdial, M.; Palincsar, A. Motivating Project-Based Learning: Sustaining the Doing, Supporting the Learning. Educ. Psychol. 1991, 26, 369-398. [CrossRef]

5. Benešová, A.; Tupa, J. Requirements for Education and Qualification of People in Industry 4.0. Procedia Manuf. 2017, 11, 2195-2202. [CrossRef]

6. Miranda, J.; Lopez, C.S.; Navarro-Tuch, S.A.; Bustamante, M.R.; Molina, J.M.; Molina, A. Open Innovation Laboratories as Enabling Resources to Reach the Vision of Education 4.0. In Proceedings of the 2019 IEEE International Conference on Engineering, Technology and Innovation (ICE/ITMC), Valbonne Sophia-Antipolis, France, 17-19 June 2019; pp. 1-7. [CrossRef]

7. Mourtzis, D.; Vlachou, E.; Dimitrakopoulos, G.; Zogopoulos, V. Cyber- Physical Systems and Education 4.0-The Teaching Factory 4.0 Concept. Procedia Manuf. 2018, 23, 129-134. [CrossRef]

8. Tvenge, N.; Martinsen, K. Integration of digital learning in industry 4.0. Procedia Manuf. 2018, 23, 261-266. [CrossRef]

9. Stark, R.; Kind, S.; Neumeyer, S. Innovations in digital modelling for next generation manufacturing system design. CIRP Ann. 2017, 66, 169-172. [CrossRef]

10. Yu, Z.; Zhou, L.; Ma, Z.; El-Meligy, M.A. Trustworthiness Modeling and Analysis of Cyber-physical Manufacturing Systems. IEEE Access 2017, 5, 26076-26085. [CrossRef]

11. Rauch, E.; Vickery, A.; Garcia, M.; Rojas, R.; Matt, D.T. Axiomatic Design based Design of a Software Prototype for Smart Shopfloor Management. MATEC Web Conf. 2018, 223, 01012. [CrossRef]

12. Bertoncelli, T.; Mayer, O.; Lynass, M. Creativity, Learning Techniques and TRIZ. Procedia CIRP 2016, 39, 191-196. [CrossRef]

13. Schallock, B.; Rybski, C.; Jochem, R.; Kohl, H. Learning Factory for Industry 4.0 to provide future skills beyond technical training. Procedia Manuf. 2018, 23, 27-32. [CrossRef]

14. Hong, J.C.; Chen, M.Y.; Wong, A.; Hsu, T.F.; Peng, C.C. Developing physics concepts through hands-on problem solving: A perspective on a technological project design. Int. J. Technol. Des. Educ. 2012, 22, 473-487. [CrossRef]

15. Lin, K.Y.; Williams, P.J. Two-stage hands-on technology activity to develop preservice teachers' competency in applying science and mathematics concepts. Int. J. Technol. Des. Educ. 2017, 27, 89-105. [CrossRef]

16. Pirttimaa, M.; Husu, J.; Metsärinne, M. Uncovering procedural knowledge in craft, design, and technology education: A case of hands-on activities in electronics. Int. J. Technol. Des. Educ. 2017, 27, 215-231. [CrossRef]

17. Niiranen, S. Supporting the development of students' technological understanding in craft and technology education via the learning-by-doing approach. Int. J. Technol. Des. Educ. 2019, 1-13 . [CrossRef]

18. Apple Inc. Challenge Based Learning: Take Action and Make a Difference; Technical Report; Apple Inc.: Cupertino, CA, USA, 2008.

19. Johnson, L.F.; Smith, R.S.; Smythe, J.T.; Varon, R.K. Challenge-Based Learning an Approach for Our Time a Research Report from the New Media Consortium; Technical Report; The New Media Consortium: Austin, TX, USA, 2009.

20. Mora-Salinas, R.; Torres, C.R.; Castillo, D.H.; Gijón, C.R.; Rodriguez-Paz, M.X. The i-semester experience: Undergraduate challenge based learning within the automotive industry. In Proceedings of the IEEE Global Engineering Education Conference, EDUCON, Dubai, United Arab Emirates, 8-11 April 2019; pp. 505-509. [CrossRef]

21. Gaskins, W.B.; Johnson, J.; Maltbie, C.; Kukreti, A. Changing the Learning Environment in the College of Engineering and Applied Science Using Challenge Based Learning. Int. J. Eng. Pedagog. (IJEP) 2015, 5, 33. [CrossRef] 
22. Chanin, R.; Santos, A.R.; Nascimento, N.; Sales, A.; Pompermaier, L.; Prikladnicki, R. Integrating challenge based learning into a smart learning environment: Findings from a mobile application development course. In Proceedings of the International Conference on Software Engineering and Knowledge Engineering, SEKE, San Francisco, CA, USA, 1-3 July 2018 ; pp. 704-706. [CrossRef]

23. Roblek, V.; Meško, M.; Krapež, A. A Complex View of Industry 4.0. SAGE Open 2016, 6, 215824401665398. [CrossRef]

24. Schmidt, R.; Möhring, M.; Härting, R.C.; Reichstein, C.; Neumaier, P.; Jozinović, P. Industry 4.0—Potentials for Creating Smart Products: Empirical Research Results. In Lecture Notes in Business Information Processing; Springer: Cham, Switzerland, 2015; Volume 208, pp. 16-27. [CrossRef]

25. International Organisation for Standardisation (ISO). ISO Occupational Health and Safety Management Systems Standard (ISO 450001); International Organization for Standardization: London, UK, 2018.

26. Office of the Deputy Director-General for Policy (DDG/P) in Consultation with LABADMIN/OSH. Review of the Implementation of ILO_ISO Agreements; Technical Report October; International Labour Office: Geneva, Switzerland, 2017.

27. Miranda, J.; Navarrete, C.; Noguez, J.; Molina-Espinosa, J.M.; Ramírez-Montoya, M.S.; Navarro-Tuch, S.A.; Bustamante-Bello, M.R.; Rosas-Fernández, J.B.; Molina, A. The Core Components of Education 4.0 in Higher Education: Three Case Studies in Engineering Education. Comput. Electr. Eng. 2021, 93, 1-27. [CrossRef]

28. Ramírez-Montoya, M.S.; Loaiza-Aguirre, M.I.; Zúñiga-Ojeda, A.; Portuguez-Castro, M. Characterization of the Teaching Profile within the Framework of Education 4.0. Future Internet 2021, 13, 91. [CrossRef]

29. Loose, C.C.; Ryan, M.G. Cultivating Teachers When the School Doors Are Shut: Two Teacher-Educators Reflect on Supervision, Instruction, Change and Opportunity during the Covid-19 Pandemic. Front. Educ. 2020, 5, 1-11. [CrossRef]

30. Jahanmir, S.; Saka, N.; Tucker, C.; Kim, S.G. Advances in Multidisciplinary Engineering; ASME Press: New York, NY, USA, 2016. [CrossRef]

31. Sarkar, S. The role of information and communication technology (ICT) in higher education for the 21st century. Science 2012, $1,30-40$.

32. Serth, S. Integrating Professional Tools in Programming Education with MOOCs. In IEEE Frontiers in Education Conference (FIE); ; IEEE: Cincinatti, OH, USA, 2019; p. 2.

33. Narasareddygari, M.R.; Brown, T.M.; Walia, G.; Radermacher, A.; Kotala, P. Using Digital Learning Objects in SEP-CyLE to Support CS1 Pedagogy An Empirical Investigation. In IEEE Frontiers in Education Conference (FIE); IEEE: Cincinatti, OH, USA, 2019; p. 8.

34. dos Santos, J.M.; Bremgartner, V.; Queiroz Neto, J.P.; Lima, H.; Pereira, M. ROBÔ-TI: Educational Robotics and Project-Based Learning Stimulating High School Students in the Information Technology Area. In IEEE Frontiers in Education Conference (FIE); IEEE: Cincinatti, OH, USA, 2019; p. 8.

35. Salas, R.P. Teaching Robotics to Undergraduate Computer Science Students: A different approach. In IEEE Frontiers in Education Conference (FIE); IEEE: Cincinatti, OH, USA, 2019; p. 7.

36. Vahid, F.; Edgcomb, A.; Lysecky, R.; Rajasekhar, Y. New web-based learning content for core programming concepts using Coral. In IEEE Frontiers in Education Conference (FIE); IEEE: Cincinatti, OH, USA, 2019; p. 5.

37. Menold, J.; Berdanier, C.; Ritter, S.; Handley, M.; Starkey, E.; Byron, M.; Grady, C.; Miiller, S.; Parkinson, M. BUILDing a community of female makers through hands-on experiences in a university MakerSpace. In IEEE Frontiers in Education Conference (FIE); IEEE: Cincinatti, OH, USA, 2019; p. 8.

38. Knox, M.E. Integration of Mixed Reality into an Engineering Laboratory Experience for Online Students. In IEEE Frontiers in Education Conference (FIE); IEEE: Cincinatti, OH, USA, 2019; p. 5.

39. Marcolino, A.S.; Praça, E.; da Silva, E.G. Towards a Practical Approach to Improve the Interdisciplinary Teaching and Learning Process through M-learning Innovative Projects. In IEEE Frontiers in Education Conference (FIE); IEEE: Cincinatti, OH, USA, 2019; p. 5 .

40. Boguski, R.; Cury, D.; Gava, T. TOM: An intelligent tutor for the construction of knowledge represented in concept maps. In IEEE Frontiers in Education Conference (FIE); IEEE: Cincinatti, OH, USA, 2019; p. 7.

41. Cheng, Q.; Lopez, F.; Hadjixenofontos, A. Integrating Introductory Data Science into Computer and Information Literacy through Collaborative Project-based Learning. In IEEE Frontiers in Education Conference (FIE); IEEE: Cincinatti, OH, USA, 2019 ; p. 5.

42. Homann Topin, L.O.; Torres, M.; Barwaldt, R.; Espíndola, D.; Castro de Freitas, A.L.; Maciel Ribeiro, L.; Pias, M.; Sartori Junior, J. Towards Machine Learning for Enhanced Maths Teaching to the Blind. In IEEE Frontiers in Education Conference (FIE); IEEE: Cincinatti, OH, USA, 2019; p. 8.

43. Davis, K.C. Teaching Database Querying in the Cloud. In IEEE Frontiers in Education Conference (FIE); IEEE: Cincinatti, OH, USA, 2019; p. 7.

44. Stöckli, S.; Schulte-Mecklenbeck, M.; Borer, S.; Samson, A.C. Facial expression analysis with AFFDEX and FACET: A validation study. Behav. Res. Methods 2018, 50, 1446-1460. [CrossRef]

45. Gutiérrez-Martínez, Y.; Navarro-Tuch, S.A.; López-Aguilar, A.A.; Bustamante-Bello, R.; Gutierrez-Martinez, Y.; Navarro-Tuch, S.A.; Lopez-Aguilar, A.A.; Bustamante-Bello, M.R. Environmental Impact for Labor Stations Learning through Emotional Domotics Analysis and Workstation Simulation. In Proceedings of the 2018 International Conference on Mechatronics, Electronics and Automotive Engineering (ICMEAE), Cuernavaca, Mexico, 27-30 November 2018; pp. 124-128. [CrossRef] 
46. Navarro-Tuch, S.A.S.; Bustamante-Bello, M.R.; Izquierdo-Reyes, J.; Avila-Vazquez, R.; Ramirez-Mendoza, R.; Jose Luis, P.H.P.H.P.H.; Gutierrez-Martinez, Y. Emotional domotics: Inhabitable home automation system for emotion modulation through facial analysis. In Intelligent Systems and Applications; Bi, Y., Kapoor, S., Bhatia, R., Eds.; Springer International Publishing: Cham, Switzerland, 2018; Volume 751, pp. 218-241. [CrossRef]

47. Navarro-Tuch, S.A.; Lopez-Aguilar, A.A.; Bustamante-Bello, M.R.; Molina, A.; Izquierdo-Reyes, J.; Curiel Ramirez, L.A. Emotional domotics: A system and experimental model development for UX implementations. Int. J. Interact. Des. Manuf. (IJIDeM) 2019, 13, 1587-1601. [CrossRef]

48. Herrera Quintero, L.F. Viviendas inteligentes ( Domótica ). Rev. Ing. E Investig. 2005, 25, 47-53.

49. International Organisation for Standardisation (ISO). Ergonomics of Human-System Interaction-Part 11: Usability: Definitions and Concepts; British Standards Institution: London, UK, 2018.

50. Kaasinen, E.; Kymäläinen, T.; Niemelä, M.; Olsson, T.; Kanerva, M.; Ikonen, V. A User-Centric View of Intelligent Environments: User Expectations, User Experience and User Role in Building Intelligent Environments. Computers 2012, 2, 1-33. [CrossRef]

51. Kraft, C. User Experience Innovation; Apress: Berkeley, CA, USA, 2012. [CrossRef]

52. Redfern, A. The Essential Guide to Classroom Practice; Routledge: London, UK, 2018. [CrossRef]

53. Lozano Alarcon, J. NORMA Oficial Mexicana, Condiciones de Iluminación en los Centros de Trabajo, NOM-025-STPS-2008; Secretaria del Trabajo y Previsión Social: Mexico City, Mexico, 2008.

54. Abascal Carranza, C.M. Norma Oficial Mexicana, Condiciones Termicas Elevadas o Abatidas-Condiciones de Seguridad e Higiene NOM-015-STPS-2001; Secretaria del Trabajo y Previsión Social: Mexico City, Mexico, 2002.

55. Abascal Carranza, C.M. NORMA Oficial Mexicana, Condiciones de Seguridad e Higiene en los Centros de Trabajo Donde se Genere Ruido. NOM-011-STPS-2001; Secretaria del Trabajo y Previsión Social: Mexico City, Mexico, 2002.

56. Levine, D.M.; Krehbiel, T.C.; Berenson, M.L. Estadística para Administración, 6th ed.; Pearson Education: Estado de México, Mexico, 2014; p. 624. [CrossRef]

57. Self, J.A.; Baek, J.S. Interdisciplinarity in design education: Understanding the undergraduate student experience. Int. J. Technol. Des. Educ. 2017, 27, 459-480. [CrossRef]

58. Brown, M.; McCormack, M.; Reeves, J.; Brooks, C.; Grajek, S. The Horizon Report Trends; Technical Report 1; EDUCAUSE Publications: Boulder, CO, USA, 2020.

59. Wallner, T.; Wagner, G. Academic Education 4.0. In International Conference on Education and New Developments; World Institute for Advanced Research and Science: Lisbon, Portugal, 2016; pp. 155-159. 